Document downloaded from:

http://hdl.handle.net/10251/58028

This paper must be cited as:

Hermosilla, T.; Palomar-Vázquez, J.; Balaguer Beser, AA.; Balsa Barreiro, J.; Ruiz Fernández, LÁ. (2014). Using street based metrics to characterize urban typologies. Computers, Environment and Urban Systems. 44:68-79.

doi:10.1016/j.compenvurbsys.2013.12.002.

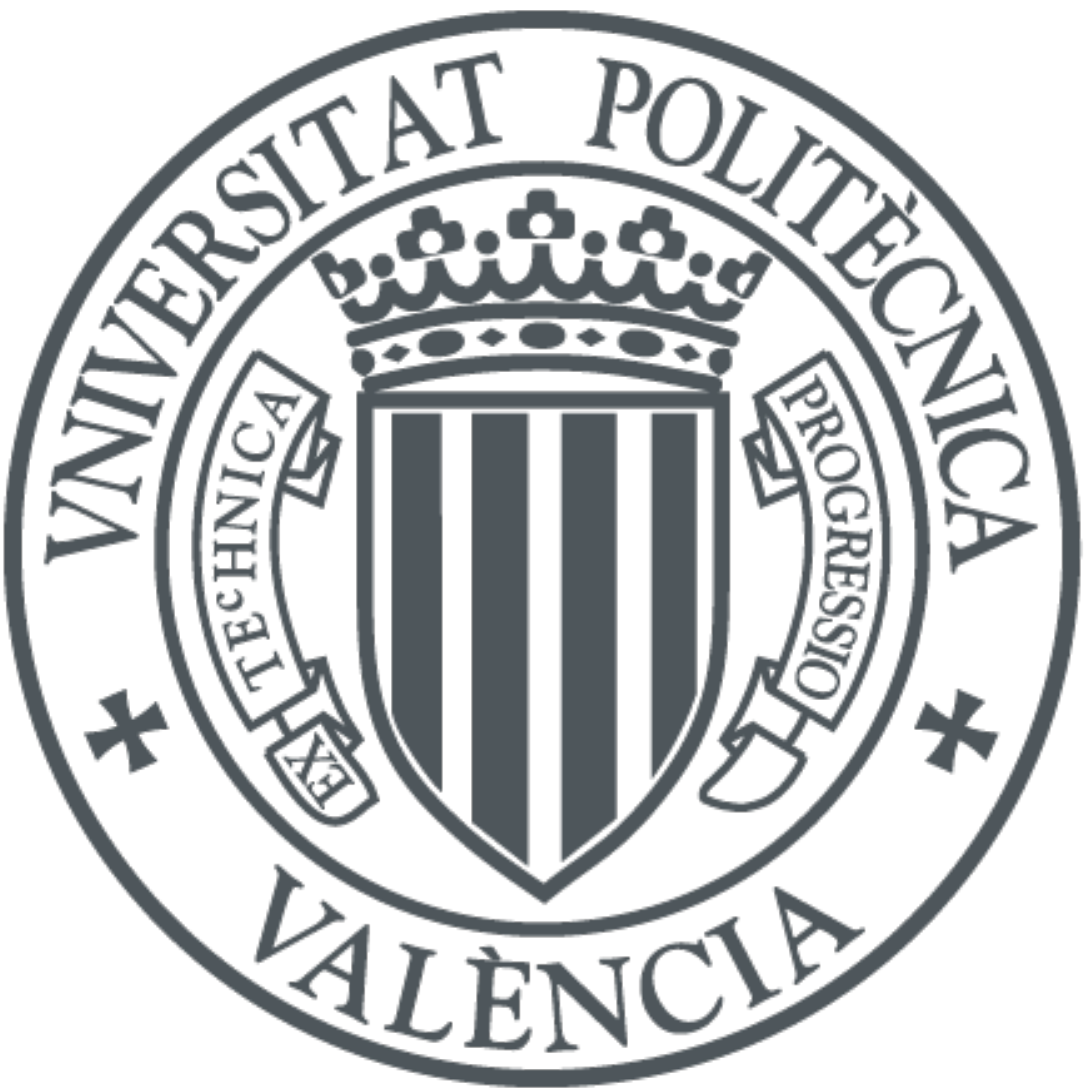

The final publication is available at

http://dx.doi.org/10.1016/j.compenvurbsys.2013.12.002

Copyright Elsevier

Additional Information 


\section{Using street based metrics to characterize urban}

\section{2 typologies}

3 T. Hermosilla ${ }^{\text {ab }}$, J. Palomar ${ }^{\text {ab }}$, A. Balaguer-Beser ${ }^{\text {ac }}$, J. Balsa-Barreiro ${ }^{\text {d }}$, L.A. Ruiz ${ }^{\text {ab }}$

4

5 a Geo-Environmental Cartography and Remote Sensing Group, Universitat Politècnica de

6 València, Camino de Vera, s/n 46022, Valencia, Spain

7 b Department of Cartographic Engineering, Geodesy and Photogrammetry, Universitat

8 Politècnica de València, Camino de Vera, s/n 46022, Valencia, Spain

$9{ }^{\mathrm{c}}$ Department of Applied Mathematics, Universitat Politècnica de València, Camino de Vera, s/n

10 46022, Valencia, Spain

11 d Department of Mathematical Methods and Representation, Universidade da Coruña, Campus

12 de Elviña s/n, 15071A Coruña, Spain

Corresponding author: Txomin Hermosilla

e-mail: txohergo@topo.upv.es

Postal address:

Departamento de Ingeniería Cartográfica, Geodesia y Fotogrametría

Camino de Vera, s/n. 46022 Valencia. SPAIN

Telephone: +34 96387000 Ext 75576

Fax Number: +34 963877559 .

\section{Abstract}

The urban spatial structure reflexes the local particularities produced during the historical development of a city. Currently high spatial resolution imagery and LiDAR data are used to derive numerical attributes to characterize the intra-urban structure and morphology. The urbanblock boundaries have been frequently used to define the units to extract metrics from the remotely sensed data. In this paper, we propose to complement those metrics with a set of descriptors of the streets surrounding the urban blocks that numerically characterize the geometry, presence of vegetation, and relationship with buildings. To carry out this purpose we also introduce a methodology to define the street area related with an urban block from which derive the urban metrics referred to the street. The assessment of these metrics is fulfilled using one-way ANOVA procedure and decision trees classifier. These results reveal that street metrics, and particularly those describing the street geometry, are suitable to enhance the 
discrimination of complex urban typologies. Thus, the overall classification accuracy increases from $72.7 \%$ to $81.1 \%$ when adding the street descriptors. The results of this study demonstrate the usefulness of the metrics describing the street properties to complement the information derived from the urban blocks and to improve the characterization of urban areas.

\section{Highlights}

We propose a set of urban metrics to describe the streets with remotely sensed data A methodology to relate the street space to urban blocks is defined

Results show that street metrics are useful to improve the characterization of cities

\section{Keywords:}

Urban morphology; urban metrics; remote sensing; high-resolution imagery; LiDAR

\section{Introduction}

Landscape metrics were defined by McGarigal and Marks (1995) as measurements that enable to numerically quantify and summarize the spatial patterns of the land-use/land-cover (LULC) classes of a geographic area. The urban spatial structure reflects the processes that occur during the historical development of a city, so urban districts constructed in different time periods show significant differences in building density and structures (Anas et al., 1989; Yu et al., 2010). The geometry of open spaces and built-up areas composing a city and their topological relationships determine the appearance of urban environments, and display local particularities related to a spatial identity (Laskari et al., 2008). Therefore, the various urban structural typologies can be depicted through metric attributes quantifying characteristics such as shape, land cover composition, spatial arrangement, or contextual relationships. The use of those urban metrics has become a trend in a wide range of studies and applications (Ji et al., 2006), e.g., environmental monitoring (Robinson, 2006; Edussuriya et al., 2011), energy efficiency assessment (Neidhart and Sester 2006; Geiß et al., 2011; Kellett et al., 2013; Tooke and Coops, 2013), socio-economic analysis (Patino and Duque, 2012; Tompalski and Wężyk, 2012; Gong et al., 2013), hydrological studies (Canters et al., 2007), or, with significant importance, in LULC mapping and change detection (Furberg and Ban 2008; Novack et al., 2010; Malinverni, 2011; Hermosilla et al., 2012a; Hermosilla et al., 2012b).

Remote sensing data have a relevant role to provide automatic and massive structural descriptions of urban areas (Puissant et al., 2012). High spatial-resolution multi-spectral information acquired from satellites or airborne sensors enable a detailed characterization of urban areas. In addition, airborne LiDAR (Light Detection And Ranging) systems facilitate a three-dimensional description of the landscape providing point clouds representing the height 
distribution of the observed terrain and the aboveground elements. When working with remotely sensed data, urban characterization is commonly undertaken applying two stage approximation methods (Bauer and Steinnocher, 2001). Initially, the principal LULC or the basic elements, such as buildings or vegetation, are identified. Then this information is analyzed in a spatial context to define urban metrics describing aspects such as the geometry, dimensions, or the area covered by buildings, vegetation, or other construction materials. In this analysis of urban morphology, remote sensing may take advantage of the physical explicitness represented by urban blocks, since roads and/or cadastral maps incontrovertibly delimit them (Yoshida and Omae, 2005). An urban block is defined as the group of private or public buildings and open space composing an island surrounded by public roads or streets (Gil et al., 2012). Using urban blocks would facilitate combining multiple datasets to analyze and characterize urban areas, and also integrating the information derived from remotely sensed data into GIS (Geographic Information Systems) (Gamba et al., 2005). As a consequence, numerous authors have employed urban blocks - or occasionally parcels - to define units from which extract metrics from high-spatial resolution images (Zhan et al., 2000; Kressler et al, 2001; Bauer and Steinnocher, 2001; Wijnant and Steenberghen, 2004; Pan et al., 2008; Wu et al., 2009; Novack et al., 2010; Vanderhaegen and Canters, 2010; Huck et al., 2011). These metrics are complemented with height information and volumetric descriptor sets whether threedimensional information is available (Yoshida and Omae, 2005; Wu et al., 2009; Yu et al., 2010; Hermosilla et al., 2012a; Heiden et al., 2012; Taubenböck et al., 2013).

In addition to bounding the blocks, urban-block cartography enables to delimitate as its complementary area the public streets. Street properties such as shape and geometry, or the presence of diverse vegetation are also factors determining the appearance of the urban space (Lillebye, 1996). Hence, the characterization of the streets surrounding an urban-block may provide a contextual frame to highlight the differences between urban structural typologies. However, the discriminative potential of attributes based on the streets have been barely explored in the literature, which have been mainly focused in the geometrical description of the streets. In this sense, Loüw and Sithole (2011) characterized urban blocks with a set of streetbased descriptors such as street width or building-street distances; Gil et al. (2012) used properties such as dimensions, orientation, accessibility, or connectivity to describe the streets. Both works considered the streets as linear features. We propose to complete and complement the geometrical description of the streets with information computed from remote sensing data. This would enable to describe deeper the urban landscape using additional characteristics derived from the streets - considering these as polygon features -, such as the presence and distribution of vegetation, or the relationships of street geometry with the surrounded buildings. 
This requires an initial process to partition the street space and to find its dependencies to the urban-blocks.

This paper aims (i) to propose a methodology for partitioning the public street space and relate it to each urban block; (ii) to define a set of urban metrics based on the streets surrounding the urban blocks; and (iii) to perform a comprehensive statistical analysis of the usefulness of the proposed metrics. This is done by studying the complementariness of the street metrics to urban blocks metrics for discriminating among several urban typologies in the metropolitan area of Valencia (Spain). The paper is structured as follows. In Section 2 the study area, the high-spatial resolution images and the LiDAR data are described. Section 3 describes the methodology followed: definition of urban typologies within the studied area, procedure to derive the street area related to the urban block, the compilation of the urban-block based metrics and the definition of street-based descriptors, and finally the methodology followed to assess the metrics. The statistics and classification results are presented and discussed in Section 4. Section 5 provides the conclusions.

\section{Study area, data and preprocessing}

We performed this study in the city of Valencia, the third most populated city in Spain. The demolition of the medieval wall and the subsequent processes of annexation of nearby villages as own neighbourhoods in the second half of the nineteenth century leaded a process of urban expansion relatively concentric to the historical city. The strong industrialization process experienced in the 1950s-1960s and the rapid increase of population produced by the urban exodus disturbed the planned urban model. The subsequent processes to connect the city to the sea directed the urban sprawl eastwards, producing an absorption of satellite historical settlements within the new city (Balsa-Barreiro and Lois-González, 2009).

Remotely sensed data - high spatial-resolution imagery and LiDAR - were acquired in the frame of the Spanish National Plan of Aerial Orthophotography (PNOA). The images were collected in August 2008, with $0.5 \mathrm{~m} /$ pixel spatial resolution, 8 bits radiometric resolution, and four spectral bands: infrared, red, green, and blue. The images are distributed orthorectified and georreferenced, panchromatic and multispectral bands fused, and with mosaicking and radiometric adjustments applied. LiDAR data were collected in September 2009 using a RIEGL LMS-Q680 laser scanner with a scan frequency of $46 \mathrm{~Hz}, 70 \mathrm{kHz}$ of pulse repetition rate and a scanning angle of $60^{\circ}$. The mean flying height was 1,300 meters, a nominal density of 0.5 points $/ \mathrm{m}^{2}$ and an average density value of 0.7 points $/ \mathrm{m}^{2}$. A normalized digital surface model (nDSM), i.e., the difference between the digital surface model (DSM) and the digital terrain model (DTM), representing the physical heights of the elements present over the terrain, was 
generated from LiDAR data. The DTM was computed using an algorithm that iteratively selects minimum elevation points and eliminates points belonging to any aboveground elements, such as vegetation or buildings (Estornell et al., 2011).

Urban block boundaries are provided in vector-format cadastral cartography with a scale of 1:1,000. These maps are produced by the Spanish General Directorate for Cadastre (Dirección General de Catastro).

Numerous urban metrics defined are based on the building and vegetation covers, which were obtained using an automatic building detection technique consisting of applying a multiplethreshold based approach over the normalized difference vegetation index (NDVI) image and the nDSM. This methodology is fully described and assessed in Hermosilla et al. (2011).

\section{Methodology}

\subsection{Urban typologies}

We defined eight urban typologies representing different historical periods of edification and urban planning of Valencia, and selected samples based on the visual analysis of the urban structure over the high-spatial resolution images. The urban typologies defined are:

- Main historical town (historicall) which constitutes the historical core of the city. Their irregular geometrical shape characterizes blocks, which are surrounded by very narrow streets and few green zones. The buildings show a variety on their heights (Figure 1.a).

- Secondary historical town (historical2): it refers to minor historical settlements integrated now within the city. Urban-blocks are spatially arranged with varied regularity, and the buildings are usually lower than in the main historical town (Figure 1.b).

- Late XIX century expansion $(r X I X)$ - denoted ensanche in Spanish - developed in regular grid plan, with significant mid-block open spaces. Although initially the height of the buildings was related to the adjacent streets, most these requirements were later modified (Figure 1.c).

- Residential areas built in 1950 and 1960 decades (r1950-60): these neighbourhoods were developed with hurry in order to shelter the displaced population due to the rural flight. This typology is composed by average-height buildings placed in barely regular urban-blocks, which are usually delimited by narrow streets (Figure 1.d).

- Residential areas from 1970 and 1980 decades (r1970-80): composed by especially tall apartment towers and open public spaces like plazas and gardens (Figure 1.e). 
- Residential areas built-up during 2000 decade ( $(2000)$ present also high buildings and abundance of gardens - both within public and private locations -, in urban-blocks bounded by wide avenues (Figure 1.f).

- Single-family suburban areas (suburban): groups of detached and semi-detached individual buildings, often surrounded by vegetation and located at certain distance of the core of the city (Figure 1.g).

- Industrial areas (industrial): planed zones populated with buildings and structures for manufacturing, transforming, repairing, storing, and distributing goods. Constructions are usually extensive and arranged to the street network (Figure 1.h).

\subsection{Urban block related street area (UBRSA) definition}

We state public street as those areas in the city that are enclosed by no urban block. The urbanblock related street area (UBRSA) polygon is the specific public street surrounding each urban block, and this is understood as the street area related by an urban block. We developed a methodology to define spatially the UBRSA polygons by triangulating the public street and detecting the intersections of the streets. As result, the street is divided in street segments, which are afterwards merged producing the UBRSA polygons related to each urban-block, from which the metrics are derived.

First, the contour of urban-blocks is simplified using the point remove algorithm, an enhanced version of the Douglas-Peucker algorithm (Douglas and Peucker, 1973), in order to remove unrelevant details and increase processing efficiency (Figure 2.a). Next, the public street polygon is extracted as the complementary area of urban block polygons (Figure 2.b).

The street polygon is then partitioned in street segments delimited by the street crossing boundaries. This process is based on the triangulation of the public street polygon, which is a computational geometry process where for a set of points in a plane (the street polygon vertices) produces a triangulated irregular network (TIN). These triangles represents a surface as a set of non-overlapping contiguous triangular facets with irregular size and shape (Fowler and Little, 1979). That way, every triangle of the TIN within the street polygon (Figure 2.c) is analysed to detect the street crossings. Thus, a triangle belongs to a street intersection area if none of its edges is adjacent to an urban block. Once these triangles are detected, street crossing boundaries are determined by drawing a line from its centroid to each of its vertices (Figure 2.d). If several adjacent triangles are contained in a street intersection, the centroid computed is the one referred to the polygon composed by all these triangles. Figure 3 shows examples of how street crossing boundaries are defined for one (Figure 3.a), two (Figure 3.b), or three (Figure 3.c) triangles contained within a street intersection. Next, the triangles are merged keeping the street crossing 
boundaries (Figure 2.e) and producing, as a result, the division of the street polygon in several street segments (Figure 2.f).

The last step is the creation of the UBRSA polygons. Thus, the UBRSA polygon of an urbanblock is produced by merging every adjacent street segment to that block. Since a street segment is likely adjacent to several urban-blocks, most UBRSA polygons of neighbouring blocks will overlap among them, as shown in Figure 4.

\subsection{Descriptive urban metrics}

We defined two groups of urban metrics: urban-block-based metrics, and street-based metrics derived from the UBRSA polygons. To characterize the urban-blocks three kinds of metrics were used: (i) descriptors of the shape and geometrical properties of urban-block polygons, (ii) geometric and volumetric attributes regarding buildings, and (iii) features describing vegetation patches. Most of these urban-block metrics, or variations thereof, have been repeatedly used in urban characterization (Boffet and Rocca-Serra, 2001; Yoshida and Omae, 2005; Neidhart and Sester, 2006; Laskari et al., 2008; Goodwin et al., 2009; Van de Voorde et al., 2009; Lu et al., 2010; Yu et al., 2010; Tooke et al., 2011; Heiden et al., 2012; Hermosilla et al., 2012a; Peeters and Etzion, 2012, Berger et al., 2013; González-Aguilera et al., 2013). The geometry of the urban-block polygons is described with the area and perimeter, meanwhile the contour complexity is numerically quantified using the shape factors: compactness, shape index, and fractal dimension. Compactness (or circularity) measures the degree to which the shape is close to a circle (Bogaert et al., 2000). Shape index estimates how similar to a square a shape is. Fractal dimension provides a numerical characterization of fractal patterns by computing their complexity as a ratio of the change in detail to the change in scale (Krummel et al., 1987; McGarigal and Marks, 1995). Buildings are described in terms number, area, height, and volume. The built-up area is characterized by means of the building coverage area $(B C A)$ and the building covered ratio $(B C R) . B C R$ is obtained by normalizing the $B C A$ by the area of the urban block, expressing the result as percentage. The number of buildings within the urban block $\left(N_{B}\right)$ is also computed. The height of the buildings is characterized using the mean $(\overline{B H})$, maximum $(\max B H)$, and standard deviation $(s d B H)$ values obtained from the $\mathrm{nDSM}$. Using this model, the volumetric properties of the buildings are also derived. In addition to the built-up volume $\left(\right.$ Volume $\left._{B}\right)$, the mean built-up volume per building $\left(\overline{\text { Volume }}_{B}\right)$, and the built-up volume normalized by the urban-block area $\left(\right.$ NVolume $\left._{B}\right)$ are computed. Analogously, vegetation metrics computed are vegetation covered area $(V C A)$, vegetation covered ratio $(V C R)$, vegetation volume, and vegetation volume normalized by urban-block area. Table 1 compiles the equations to compute the urban-block based metrics. 
The street-based urban metrics characterize the UBRSA in terms of four aspects: geometry, neighbouring block connectivity, presence of vegetation, and relationship with the urban-block buildings. The geometry of the streets is quantified by means of the area $\left(A r e a_{U B R S A}\right)$ and descriptors of the width of the street segments composing the UBRSA of an urban block. The width of each street segment is computed by initially enclosing an oriented bounding rectangle. The major axe orientation is then used as guide to draw perpendicular transects separated apart one metre, as it is shown in Figure 5.a. The median width of all transects is assigned as the specific width of the street segment. Finally, the mean $(\overline{S W})$, standard deviation $(s d S W)$, minimum $(\min S W)$, and maximum $(\max S W)$ of the width of the adjacent street segments are computed (see Figure 5.b). The number of neighbouring urban blocks $\left(N N_{U B}\right)$ of each UBRSA polygon provides the degree of neighbouring block connectivity. The vegetation metrics characterizing the streets are vegetation covered area $\left(V C A_{U B R S A}\right)$, vegetation covered ratio $\left(V C R_{U B R S A}\right)$, vegetation volume (Volume VUBRSA ), and vegetation volume normalized by UBRSA area $\left(\right.$ nVolume $\left._{V U B R S A}\right)$. The last group of street-based metrics aims to relate the structure of the buildings of an urban block to the geometry of the surrounding streets, and to exploit the dependency relationships among them. The metrics computed are the ratio between the BCA of a block and the area of its UBRSA (Ratio Area $_{\text {) }}$, and the ratio between the built-up volume within a block normalized by the UBRSA area $\left(\right.$ Ratio $\left._{\text {Volume }}\right)$. Table 2 summarizes the equations to compute the street based metrics.

\subsection{Assessment of the metrics}

Initially, we studied the metrics independently by applying the one-way ANOVA procedure to estimate the ability of each urban metric to describe the differences among the eight urban typologies. The F-test in the ANOVA table, which is defined as the ratio of the between-group variance estimate to the within-group variance estimate, evaluate whether there are any significant differences amongst the means. In addition, the Fisher's least significant difference (LSD) procedure (Milliken and Johnson 1992) is also employed to determine which means are significantly different from which others in such a way that if two means are the same then their intervals will overlap 95\% of the time. To avoid the effects of outliers, we also have applied the Kruskal-Wallis test to compare median instead of mean values.

To evaluate the performance of the proposed street urban metrics, we performed two classifications: one considering the urban-block metrics, and other combining these with the street metrics. We applied the C5.0 algorithm using See5.0 software (Quinlan, 1993). Preceding the creation of the rules for each classification, an initial selection of the metrics was performed in order to reduce number of descriptive attributes to be used into the classifier, in addition to estimate their impact in the classification. This process, denoted winnow (Littlestone, 1988), 
numerically estimates the importance of the descriptive attributes for the particular classification problem analyzed, enabling to choose the useful metrics among unhelpful ones. The selected attributes are then ranked by importance, numerically showing for each attribute the percentage increase in error rate if that attribute is excluded from the classification.

The C5.0 algorithm defines decision trees were constructed based on training samples. A decision-tree is defined as a set of conditions organized in a hierarchical structure in such a way that the class assigned to an object is determined following the conditions that are fulfilled from the initial dataset to any of the assigned classes. A two-step pruning process was applied to the decision trees to reach a better predictive accuracy by reducing the over-fitting. Initially, the degree to which the initial tree fits the training data was constrained by fixing a minimum of five training cases that each node must follow. Later, the parts of the decision trees predicted to have a relatively high error rate were removed. This was first applied to every sub-tree to decide if it should be replaced by a leaf or sub-branch or not, and then a global stage considers the performance of the tree as a whole (Murthy, 1998).

Decision trees were applied in combination with the boosting technique, which allows for the increase of the classifier accuracy by constructing multiple decision trees (Freund et al., 1999). This technique relies on assigning weights to the training samples, so the greater the weight of a sample, then the greater its influence on the classifier. After each tree construction, weights are adjusted to show the model performance. Samples erroneously classified maintain their assigned weights, whereas correctly classified samples reduce their weights. As result, the model obtained in the subsequent iteration provides more relevance to the earlier incorrectly classified samples. We used ten iterations to define the rules. After the construction of the decision tree set, the class assigned to an object considers the estimated error produced in the construction of each tree, being the weight assigned to a tree inversely proportional to the estimated error. The summation of the weights of the trees predicting the same class is then computed, and the class with the highest value is finally assigned.

The accuracy of the classification models was assessed using leave-one-out cross-validation technique (Fukunaga, 1990). Both classifications were evaluated by analyzing the confusion matrix (Congalton, 1991), which relates the class assigned to each test sample with its reference class. We computed the overall accuracies of the classifications, and for each class, producer's and user's accuracies, which respectively estimate the mission and commission errors.

\section{Results and discussion}


The one-way ANOVA results show that the p-value of the F-test for all metrics is lower than 0.05 , meaning that there are statistically significant differences between the mean values of the urban typologies with 95\% confidence level. In addition, the results of the Kruskal-Wallis test show significant differences for all variables among the medians of the eight urban typologies with 95\% confidence. Table 3 identifies with letters (A, B, C, etc.) the resulting homogeneous groups using the Fisher's LSD multiple comparison procedure to discriminate among the means. Figure 6 visually shows examples of buildings and vegetation occupation and height distribution for the various urban typologies defined. Finally, Figure 7 and Figure 8 illustrate the relationship of the urban typologies with the urban block metrics and the street metrics, respectively, using box-and-whisker plots showing median, interquartile range (IQ), and extreme values. Circles indicate atypical outliers (values $1.5-3 \times \mathrm{IQ}$ ), and asterisk represents extreme outliers (values $>3 \times I Q$ ).

As Table 3 shows, when only urban block metrics are considered, it is difficult to discriminate among both historical-town typologies (historicall and historical2), since few urban metrics enable to establish significant differences between them, i.e., mean built-up height, maximum built-up height, vegetation covered ratio, and normalized vegetation volume. As seen in Figure 7.a, buildings from historical2 typology are lower than the ones from historicall, and also the coverage and volume of vegetation inside the urban-blocks are lower. One of the most noteworthy dissimilarities between both historical typologies is expressed by the street geometry descriptors, as evidenced the statistically significant differences showed by the metrics: mean street width, maximum street width, and minimum street width. Typically, historicall and historical2 categories show narrower streets than the rest of urban typologies (Figure 8.a and Figure 8.b). There is also a clear difference in mean and median values of both historical-town typologies when taking into account the vegetation in the streets. Thus, historical2 presents substantial lower values for UBRSA vegetation covered ratio metric, as Figure 8.c shows.

The mean and median values of the metrics characterizing the urban-block area and perimeter are significantly larger for industrial than for the rest of typologies (Figure7.d). Nevertheless, those geometry-related metrics show similar values for r1950-60, r1970-80, r2000, and suburban. Urban-block shape descriptors (compactness, shape index, and fractal dimension) do distinguish among those urban typologies, as seen in Table 3, although in this case the mean reached for industrial is not significantly different from that obtained in both historical typologies. In this case, the public street area surrounding each urban block (Area $\mathrm{UBRSA}_{\text {) }}$ enables to discriminate among $r 1950-60, r 1970-80$, and $r 2000$ urban typologies. 
The metrics describing the height of the buildings show that lowest heights are given for suburban typology, followed by industrial and historical2 (Figure 7.a). The high variability presented by $r 2000$ typology on the mean built-up height values is especially noticeable (Figure 7.b). Building coverage area values are strongly linked to the attributes characterizing the urban block dimensions, which determine the range of values that this metric can achieve. BCR avoids that limitation and it allows to discriminate among r2000, suburban, and industrial, and these from the rest of categories, since urban blocks containing these typologies are usually not completely occupied by constructions. This is particularly remarkable for suburban typology (Figure 7.e). Moreover, the ratio between the built-up coverage area and the UBRSA area promote the distinction among $r X I X, r 1970-80$, and $r 2000$. That metric values decrease for these typologies as more recent the constructions are (Figure 7.e and Figure 8.e).

The vegetation covered ratio inside urban blocks also significantly discriminates suburban among the other typologies (Figure7.c). This metric, however, is not as efficient in distinguishing the rest of classes, especially historicall, $r X I X$, and r1970-80 (Table 3). If we consider the distribution of vegetation in the streets surrounding the urban blocks through the UBRSA vegetation covered ratio metric, it is noticeable that r1950-60 lacks of green zones (Figure 8.c). Accounting the vegetation volume in the streets, the normalized UBRSA vegetation volume metric enables to discriminate $r X I X$ from the rest of categories (Figure 8.d). This typology, given in consolidated areas, has a profuse abundance of voluminous vegetation in public spaces. Additionally, this metric permits to difference $r 2000$ from $r X I X, r 1970-80$, and suburban, because vegetation in more recently built up neighbourhoods, though plentiful, is less voluminous. Complementing the above mentioned metrics we found that the ratio between the built-up coverage area within an urban block and the UBRSA area (Ratio ${ }_{\text {Area }}$ ) enables to separate most recent constructions ( $r 2000$ and suburban) from the oldest (historicall and $r X I X$ ) as is shown in Figure 8.d and Table 3. In turn, the ratio between the built-up volume and the

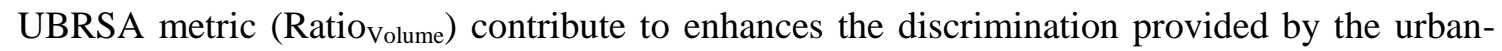
block metrics: built-up volume and mean built-up volume (Figure 7.f), by boosting the differences concerning $r X I X$ and suburban.

The results of applying the winnow algorithm show that the vegetation covered ratio is determined as the most relevant classification attribute when only considering urban block metrics, as shown in Table 5. This metric, as well as vegetation covered area, vegetation volume, and normalized vegetation volume, enables to easily distinguish suburban from other typologies (Figure 7.c). Furthermore, the vegetation covered ratio enables discriminate between historical2 and historicall, and historicall with r2000 and suburban (Table 3). This metric reaches the highest F-ratio value in the one-way ANOVA procedure among all analyzed 
metrics. The height of the buildings is also relevant being the mean built-up height ranked the $2^{\text {nd }}$, and the standard deviation of the buildings the $4^{\text {th }}$.

When urban-block and street metrics are combined the mean street-width value is ranked as the most significant attribute. These findings are in line with the reported by Loüw and Sithole (2011), who also stated the mean street-width as the most efficient attribute for classification. Although the metrics characterizing aspects of the streets different to the geometry - such as vegetation, or street geometry-buildings ratios - present a lower overall impact, they are still suitable for discriminating some particular urban typologies, as shown in Table 3.

The addition of metrics describing the streets to the classification process substantially increases the overall accuracy from $72.7 \%$ to $81.1 \%$, which verifies that the combination of different types and contextual levels of characteristics provides a multidimensional description that significantly improves the characterization of urban structural typologies (Table 5). This outcome is consistent with the results reported by several authors (Wu et al., 2009; Gil et al., 2012; Hermosilla et al., 2012a).

Analyzing the particular user's and producer's accuracies reached by the urban typologies (Figure 9), suburban areas are better classified when only considering urban block metrics, reaching $91 \%$ and $98 \%$ for the user's and producer's accuracies, respectively. That is because this typology has a remarkably different appearance, featuring many vegetation and low buildings, and also the metrics describing those features are listed as the most significant for the classification (Table 4). The addition of the street metrics, however, has very limited effect on the accuracy of suburban typology. On the other hand, although historicall reaches fair user's and producer's accuracies, $76 \%$ and $80 \%$ respectively, with the urban block metrics. When the description of streets is included in the classification model, both indices have significantly increase up to $92 \%$. The lowest accuracies are reached for $r 1950-60$ and $r 1970-80$, which are transition typologies constructed between different eras. The addition of street metrics improves the discrimination of these typologies. This is in part accomplished due the contribution of the metrics: mean street width, vegetation covered ratio of UBRSA, and Ratio ${ }_{\text {Area }}$, which cause notable accuracy increases for $r 1950-60, r 1970-80$, and also $r 2000$. Additionally to these accuracy increments, the street metrics remarkably help to diminish the confusion between r1950-60 and r1970-80 with historicall, as well as r1950-60 and r2000 with r1970-80. Overall, r1970-80 typology has the largest number of outliers in the metrics ranked as most significant in by winnow algorithm (see Figure 7 and Figure 8), which limits the positive effects of adding street metrics to eliminate the errors given between this class and rXIX and r1950-60, respectively. 


\section{Conclusions}

441 This paper presents a set of urban metrics based on the description of the streets to quantify the

442 various spatial patterns of the neighbourhoods constructed in different periods. These street 443 metrics are proposed to complement the attributes derived from the urban blocks, providing a 444 contextual frame to account the dissimilarities between the various construction typologies. We 445 extract the urban metrics from high-spatial resolution multi-spectral images, airborne LiDAR 446 data, and cadastral cartography containing the urban block boundaries. The performance of the 447 street metrics is assessed for distinguishing among eight urban typologies within the 448 metropolitan area of Valencia (Spain).

450 The results of the one-way ANOVA test show how the proposed street metrics help to establish 451 statistically significant differences among some urban typologies where the urban block metrics 452 present particular limitations. In addition, when analysing the importance of the urban metrics 453 for the classification with the winnow algorithm, mean street width is revealed the most 454 significant attribute, along with vegetation covered ratio per block and mean height of the 455 buildings, and followed distantly by the building coverage ratio. Other street metrics 456 characterizing aspects such as the distribution of vegetation in the street, or relationships 457 between street geometry and buildings present a lower importance, but they are also appropriate 458 for distinguishing among some urban typologies. The combination of the urban block attributes 459 together with the street metrics causes an increase of the overall classification accuracy from $46072.7 \%$ up to $81.1 \%$ with respects to use only urban block metrics. The addition of the street 461 metrics positively affects to all the urban typologies, being the most benefited classes the main historical town, and residential areas constructed during 1950-1960 and 1970-1980.

464 This paper shows that use of metrics describing diverse properties of the streets provides a 465 further description of the cities that complements the attributes extracted from the urban blocks. 466 Thus, the outcomes of this study demonstrate the convenience of describing the street properties 467 in order to provide useful urban metrics for all those applications requiring a precise 468 characterization of the urban areas. This is important to note that the results achieved here show 469 the local significance of the defined metrics for the specific case and urban typologies studied. 470 Nevertheless, those descriptors may consistently be applied in diverse scenarios, the importance 471 of these metrics varying to highlight the particular structural differences of the analysed cities.

\section{Acknowledgements}


474 The authors appreciate the financial support provided by the Spanish Ministry of Science and 475 Innovation and FEDER in the framework of the project CGL2010-19591/BTE, and the material 476 support of the Spanish Instituto Geográfico Nacional (IGN). 
478 Anas, A., Arnott, R., \& Small, K. A. (1998). Urban spatial structure. Journal of economic literature, 36(3), pp. 1426-1464.

480

Balsa-Barreiro, J., and Lois-González, R.C. (2009). Changes in the urban model of the city of Valencia (Spain): An analysis from the point of view of the published cartography. In Urban Geography Commision, International Geographical Union (IGU/UGI): Emerging Urban Transformations, 2009 Meeting \& International Conference on Multilayered Cities and Urban Systems (30 July-10 August). CTOS, Osmana University, Hyderabad, India.

Bauer, T. and Steinnocher, K. (2001). Per-parcel land use classification in urban areas applying a rule-based technique. GeoBIT/GIS, 6, pp. 24-27.

487 Berger, C., Voltersen, M., Eckardt, R., Eberle, J., Heyer, T., Salepci, N., ... \& Pacifici, F. (2013). Multi-Modal and Multi-Temporal Data Fusion: Outcome of the 2012 GRSS Data Fusion Contest. IEEE journal of selected topics in applied earth observations and remote sensing, 6(3), pp. 1324-1340.

Boffet, A., and Serra, S. R. (2001). Identification of spatial structures within urban blocks for town characterization. In Proceedings of 20th International Cartographic Conference, pp. 1974-1983.

494

Bogaert, J., Rousseau, R., Hecke, P.V. \& Impens, I. (2000). Alternative area-perimeter ratios for 495 measurement of 2D shape compactness of habitats. Applied Mathematics and Computation, 111 (1), pp. 71-85.

Canters F., Van de Voorde T., Batelaan O., Dams J., Cornet Y., Binard M., Goossens G., 498 Devriendt D., Tack F., Engelen G., Lavalle C., Barredo J. (2007). Measuring and Modeling Urban Dynamics: Impact on Quality of Life and Hydrology. Objectives and Methodology, In 500 Proceedings of the IEEE International Geoscience and Remote Sensing Symposium (IGARSS 2007), Barcelona, Spain, July 23-27, 2007, pp. 1994-1997.

502 Congalton, R., (1991). A review of assessing the accuracy of classifications of remotely sensed 503 data. Remote Sensing of Environment, 37(1), pp. 35-46

504 Connors, J. P., Galletti, C. S., \& Chow, W. T. (2013). Landscape configuration and urban heat 505 island effects: assessing the relationship between landscape characteristics and land surface 506 temperature in Phoenix, Arizona. Landscape Ecology, 28(2), pp. 271-283.

507 Douglas, D. H., \& Peucker, T. K. (1973). Algorithms for the reduction of the number of points 508 required to represent a digitized line or its caricature. Cartographica: The International Journal 509 for Geographic Information and Geovisualization, 10(2), pp. 112-122. 
510 Edussuriya, P., Chan, A., \& Ye, A. (2011). Urban morphology and air quality in dense

511 residential environments in Hong Kong. Part I: District-level analysis. Atmospheric

512 Environment, 45(27), pp. 4789-4803.

513 Estornell, J., Ruiz, L. A., Velázquez-Martí, B., Hermosilla, T., (2012). Assessment of factors

514 affecting shrub volume estimations using airborne discrete-return LiDAR data in Mediterranean

515 areas. Journal of Applied Remote Sensing, 6, pp. 063544-1-063544-10.

516 Fowler, R. J., and Little, J. J. (1979). Automatic extraction of irregular network digital terrain

517 models. In ACM SIGGRAPH Computer Graphics, 13(2), pp. 199-207.

518 Freund, Y., Schapire, R., \& Abe, N. (1999). A short introduction to boosting. Journal-Japanese

519 Society For Artificial Intelligence, 14(771-780), p. 1612.

520 Fukunaga, K., (1990). Introduction to Statistical pattern recognition. (2 ${ }^{\text {nd }}$ ed.), New York:

521 Academic Press, ISBN: 978-0122698514, p. 592.

522 Furberg, D., and Ban, Y. (2008). Satellite monitoring of urban sprawl and assessing the impact

523 of land cover changes in the Greater Toronto Area. In The International Archives of The

524 Photogrammetry, Remote Sensing and Spatial Information Sciences, ISPRS Congress, Beijing.

525 pp. 131-136.

526 Gamba, P., Dell'Acqua, F., \& Dasarathy, B. V. (2005). Urban remote sensing using multiple

527 data sets: Past, present, and future. Information Fusion, 6(4), pp. 319-326.

528 Gil, J., Beirão, J. N., Montenegro, N. \& Duarte, J. (2009). On the discovery of urban typologies:

529 data mining the many dimensions of urban form. Urban Morphology, 16(1), pp. 27-40.

530 Gong, C., Yu, S., Joesting, H., \& Chen, J. (2013). Determining socioeconomic drivers of urban 531 forest fragmentation with historical remote sensing images. Landscape and Urban Planning, 532117, pp. 57-65.

533 González-Aguilera, D., Crespo-Matellan, E., Hernández-López, D., \& Rodríguez-Gonzálvez, P. 534 (2013). Automated Urban Analysis Based on LiDAR-Derived Building Models. Geoscience 535 and Remote Sensing, IEEE Transactions on, 51(3), pp. 1844-1851.

536 Geiß, C., Taubenböck, H., Wurm, M., Esch, T., Nast, M., Schillings, C., \& Blaschke, T. (2011).

537 Remote sensing-based characterization of settlement structures for assessing local potential of 538 district heat. Remote Sensing, 3(7), pp. 1447-1471.

539 Goodwin, N. R., Coops, N. C., Tooke, T. R., Christen, A., \& Voogt, J. A. (2009).

540 Characterizing urban surface cover and structure with airborne lidar technology. Canadian 541 Journal of Remote Sensing, 35(3), pp. 297-309. 
542 Heiden, U., Heldens, W., Roessner, S., Segl, K., Esch, T. \& Mueller, A. (2012). Urban structure

543 type characterization using hyperspectral remote sensing and height information. Landscape

544 and Urban Planning, 105(4), pp. 361-375.

545 Hermosilla, T., Ruiz, L.A., Recio, J.A., Estornell J. (2011). Evaluation of Automatic Building 546 Detection Approaches Combining High Resolution Images and LiDAR Data. Remote Sensing 547 3(6), pp. 1188-1210.

548 Hermosilla, T., Ruiz, L. A., Recio, J. A., \& Cambra-López, M. (2012a). Assessing contextual 549 descriptive features for plot-based classification of urban areas. Landscape and Urban 550 Planning, 106(1), pp. 124-137.

551 Hermosilla, T., Gil-Yepes, J. L., Recio, J. A., \& Ruiz, L. A. (2012b). Change Detection in Peri552 urban Areas Based on Contextual Classification. Photogrammetrie-Fernerkundung553 Geoinformation, 2012(4), pp. 359-370.

554 Huck, A., S. Hese, \& E. Banzhaf, (2011). Delineating parameters for object-based urban 555 structure mapping in Santiago de Chile using QuickBird data. The International Archives of the 556 Photogrammetry, Remote Sensing and Spatial Information Sciences, 38 (4/W19), 6p.

557 Ji, W., Ma, J., Twibell, R. W., \& Underhill, K. (2006). Characterizing urban sprawl using multi558 stage remote sensing images and landscape metrics. Computers, Environment and Urban 559 Systems, 30(6), pp. 861-879.

560 Kellett, R., Christen, A., Coops, N. C., van der Laan, M., Crawford, B., Tooke, T. R., \& 561 Olchovski, I. (2013). A systems approach to carbon cycling and emissions modeling at an urban 562 neighborhood scale. Landscape and Urban Planning, 110, pp. 48-58.

563 Kressler, F. P., Bauer, T. B., \& Steinnocher, K. T. (2001). Object-oriented per-parcel land use 564 classification of very high resolution images. In Remote Sensing and Data Fusion over Urban 565 Areas, IEEE/ISPRS Joint Workshop 2001, pp. 164-167.

566 Krummel, J.R., Gardner, R.H., Sugihara, G., O’Neill, V. \& Coleman, P.R. (1987). Landscape 567 patterns in a disturbed environment. OIKOS, 48(3), pp. 321-324.

568 Laskari, S., Hanna, S., \& Derix, C. (2008). Urban identity through quantifiable spatial 569 attributes: Coherence and dispersion of local identity through the automated comparative 570 analysis of building block plans. In Proceedings of the third international conference on design 571 computing and cognition, Dordrecht, The Netherlands, pp. 615-634.

572 Lillebye, E. (1996). Architectural and functional relationships in street planning: an historical 573 view. Landscape and Urban Planning, 35(2), pp. 85-105. 
574 Littlestone, N. (1988). Learning quickly when irrelevant attributes abound: A new linear-

575 threshold algorithm. Machine learning, 2(4), pp. 285-318.

576 Löuw, J., and Sithole, G. (2011). Context Based Detection of Urban Land Use Zones. Doctoral 577 dissertation, University of Cape Town.

578 Lu, Z., Im, J., Quackenbush, L., \& Halligan, K. (2010). Population estimation based on multi579 sensor data fusion. International Journal of Remote Sensing, 31(21), pp. 5587-5604.

580 Malinverni, E. S. (2011). Change Detection Applying Landscape Metrics on High Remote

581 Sensing Images. Photogrammetric Engineering \& Remote Sensing, 77(10), pp. 1045-1056.

582 McGarigal, K. and Marks, B. J. (1995). Spatial pattern analysis program for quantifying 583 landscape structure. Gen. Tech. Rep. PNW-GTR-351. US Department of Agriculture, Forest 584 Service, Pacific Northwest Research Station.

585 Milliken, G.A. and Johnson, D.E. (1992). Analysis of messy data, Vol. 1, Designed 586 experiments. Chapman \& Hall/CRC. ISBN 10: 0412990814.

587 Murthy, S.K. (1998). Automatic construction of decision trees from data: A multi-disciplinary 588 survey. Data Mining and Knowledge Discovery, 2(4), pp. 345-389.

589 Neidhart, H., and Sester, M. (2004). Identifying building types and building clusters using 3-D 590 laser scanning and GIS-data. In Geo-Imagery Bridging Continents, XXth ISPRS Congress, 591 Istanbul, pp. 715-720.

592 Novack, T., Kux, H. J. H., Feitosa, R. Q., \& Costa, G. A. (2010). Per block urban land use 593 interpretation using optical VHR data and the knowledge-based system Interimage. The 594 International Archives of the Photogrammetry, Remote Sensing and Spatial Information 595 Sciences, 38(4/C7), 6p.

596 Pan, X. Z., Zhao, Q. G., Chen, J., Liang, Y., \& Sun, B. (2008). Analyzing the variation of 597 building density using high spatial resolution satellite images: the example of Shanghai City. 598 Sensors, 8(4), pp. 2541-2550.

599 Patino, J. E., and Duque, J. C. (2013). A review of regional science applications of satellite 600 remote sensing in urban settings. Computers, Environment and Urban Systems, 37(1), pp. 1-17.

601 Peeters, A., \& Etzion, Y. (2012). Automated recognition of urban objects for morphological 602 urban analysis. Computers, Environment and Urban Systems, 36(6), pp. 573-582.

603 Puissant, A., Zhang, W. \& Skupinski, G. (2012). Urban morphology analysis by high and very 604 high spatial resolution remote sensing. International Conference on Geographic Object-Based 605 Image Analysis 4, (GEOBIA), Rio de Janeiro, 7-9 May, pp. 524-529. 

ISBN: 1-55860-238-0, p. 302.

Robinson, D. (2006). Urban morphology and indicators of radiation availability. Solar energy, 80(12), pp. 1643-1648.

Taubenböck, H., Klotz, M., Wurm, M., Schmieder, J., Wagner, B., Wooster, M., \& Dech, S. 611 (2013). Delineation of Central Business Districts in mega city regions using remotely sensed 612 data. Remote Sensing of Environment, 136, pp. 386-401.

613 Tompalski, P. and Wezyk, P. (2012). LIDAR and VHRS Data for Assessing Living Quality in 614 Cities: An Approach Based on 3D Spatial Indices. International Archives of Photogrammetry 615 and Remote Sensing, (XXXIX-B6), pp. 173-176.

616 Tooke, T. R., vanderLaan, M., Coops, N., Christen, A., \& Kellett, R. (2011). Classification of 617 residential building architectural typologies using LiDAR. In Proceedings of the Joint Urban 618 Remote Sensing Event 2011 (11-13 April), Munich, Germany, pp. 221-224.

619 Tooke, T. R. and Coops, N. C. (2013). A Review of Remote Sensing for Urban Energy System 620 Management and Planning. In Proceedings of the Joint Urban Remote Sensing Event 2013 (2162123 April). Sao Paulo, Brazil, pp. 167-170.

622 Vanderhaegen, S. and Canters, F. (2010). Using remote sensing data for improving the 623 distinction between distinct types of urban land use and form using spatial metrics. In 624 Proceedings of the 30th EARSeL Symposium: Remote Sensing for Science, Education and 625 Natural and Cultural Heritage, Paris, 31 May- 3 June, European Association of Remote 626 Sensing Laboratories, pp.757-764.

627 Van der Geer, J., Hanraads, J. A. J., \& Lupton, R. A. (2010). The art of writing a scientific 628 article. Journal of Scientific Communications, 163, pp. 51-59.

629 Wijnant, J. and Steenberghen, T. (2004). Per-parcel classification of urban ikonos imagery. 7th 630 AGILE Conference on Geographic Information Science, Heraklion, 29 April-1 May, pp. 447631455.

632 Wu, S.S., Qiu, X., Usery, E. L. \& Wang, L. (2009). Using geometrical, textural, and contextual 633 information of land parcels for classification of detailed urban land use. Annals of the 634 Association of American Geographers, 99(1), pp. 76-98.

635 Yoshida, H., and Omae, M. (2005). An approach for analysis of urban morphology: methods to 636 derive morphological properties of city blocks by using an urban landscape model and their 637 interpretations. Computers, environment and urban systems, 29(2), pp. 223-247. 
638 Yu, B., Liu, H., Wu, J., Hu, Y. \& Zhang, L. (2010). Automated derivation of urban building 639 density information using airborne LiDAR data and object-based method. Landscape and 640 Urban Planning, 98(3-4), pp. 210-219.

641 Zhan, Q., Molenaar, M. \& Gorte, B. (2000). Urban land use classes with fuzzy membership and 642 classification based on integration of remote sensing and GIS. The International Archives of 643 Photogrammetry and Remote Sensing, 33(B7/4; PART 7), pp. 1751-1759.

644

645 


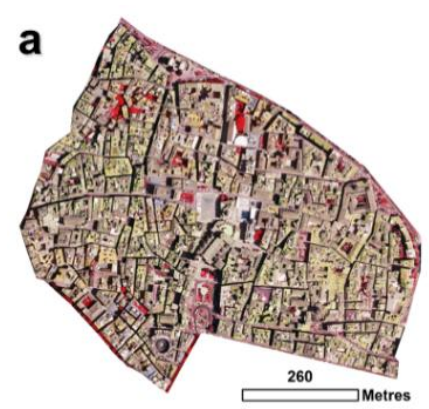

b

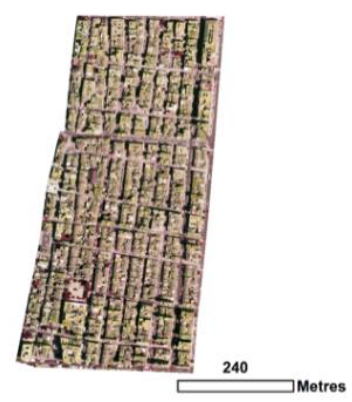

e

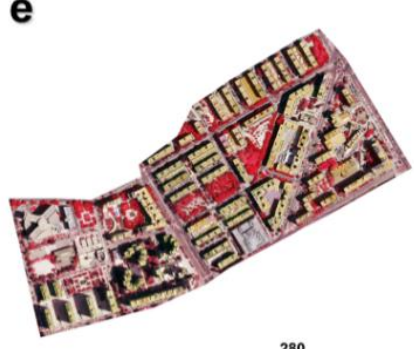

$\mathbf{f}$

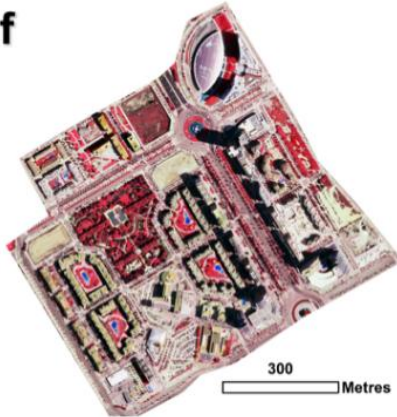

c

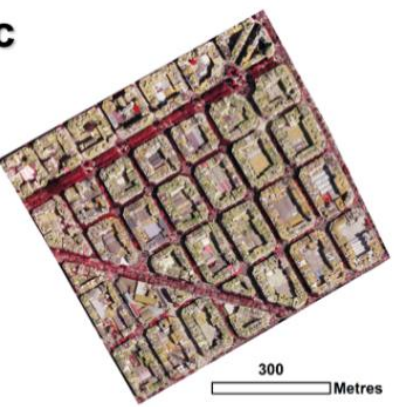

g

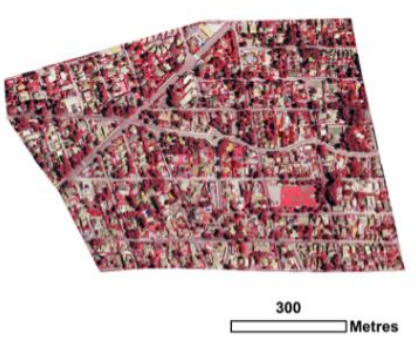

d

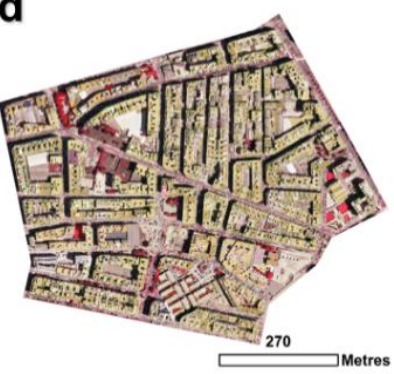

h

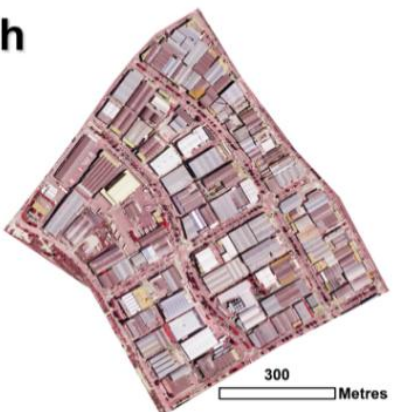

646

647

648

649

650

651

Figure 1. Examples of the urban typologies defined in a colour infrared composition: (a) Main historical town (historical1), (b) secondary historical town (historical2), (c) late XIX century expansion (rXIX), (d) 1950-1960s residential areas (r1950-60), (e) 1970-1980s residential areas

652 


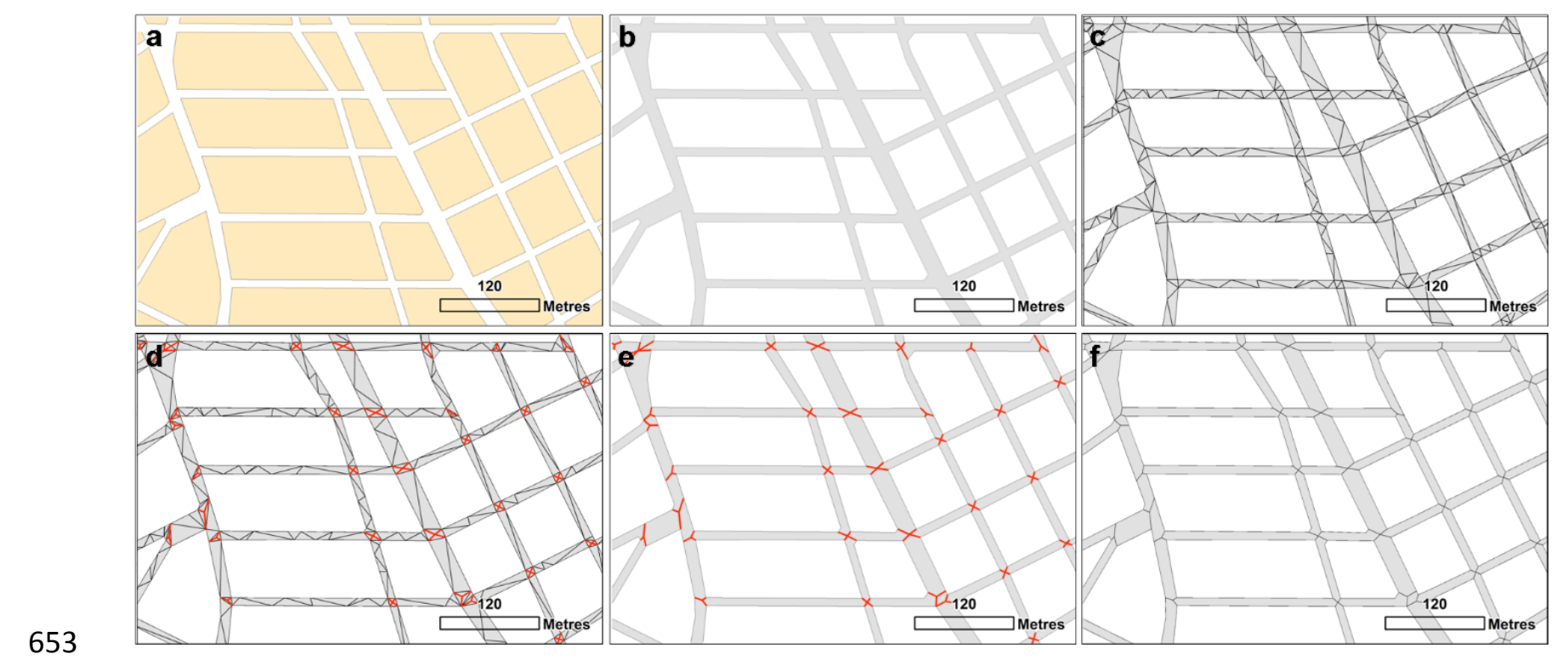

654 Figure 2. Steps followed to segment the public street: (a) simplified urban-blocks; (b) street 655 polygon, computed as the complementary of the urban-blocks (in grey); (c) triangulated 656 irregular network (TIN) of the street polygon; (d) identification of triangles within street 657 crossings, computation of centroids, and delineation of street crossing boundaries (in red); (e) 658 combination of neighbouring triangles; (f) resulting street segments.

659 


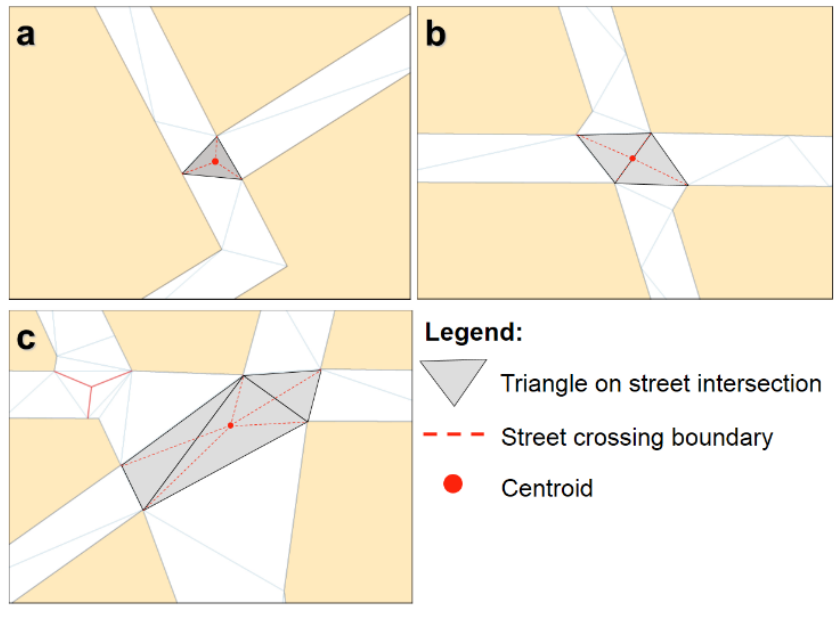

661 Figure 3. Definition of street crossing boundaries for street intersections composed by (a) one, 662 (b) two, and (c) three triangles.

663 


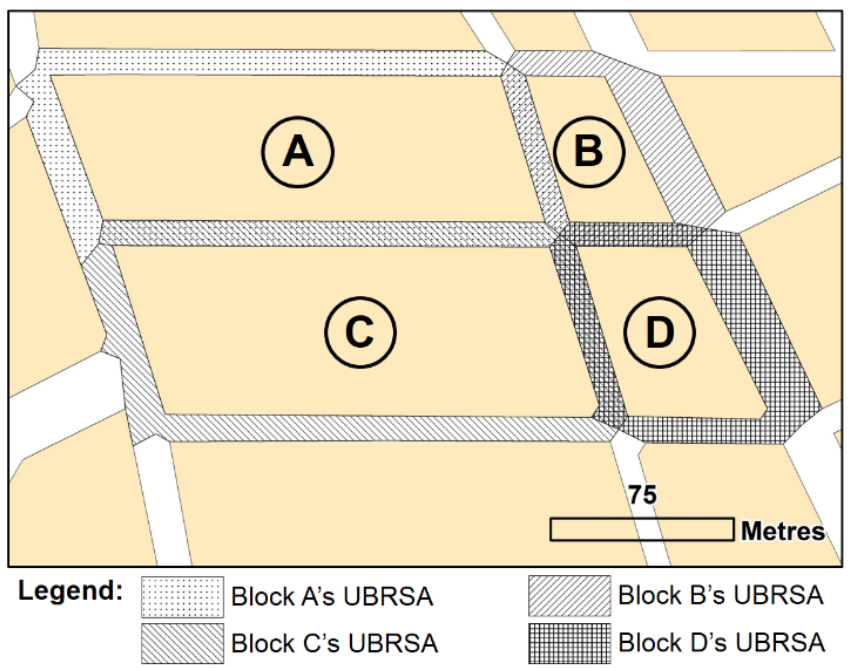

665

Figure 4. Example of overlapping urban-block related street area (UBRSA) polygons. 666 


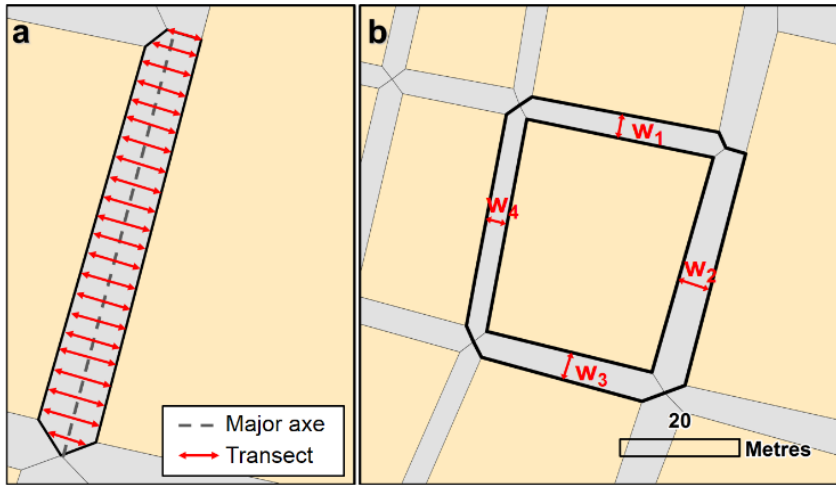

668 Figure 5. (a) Scheme of transects extracted to compute the median width value characterizing a 669 street segment. (b) Street segments conforming a UBRSA used to derive street width metrics. 

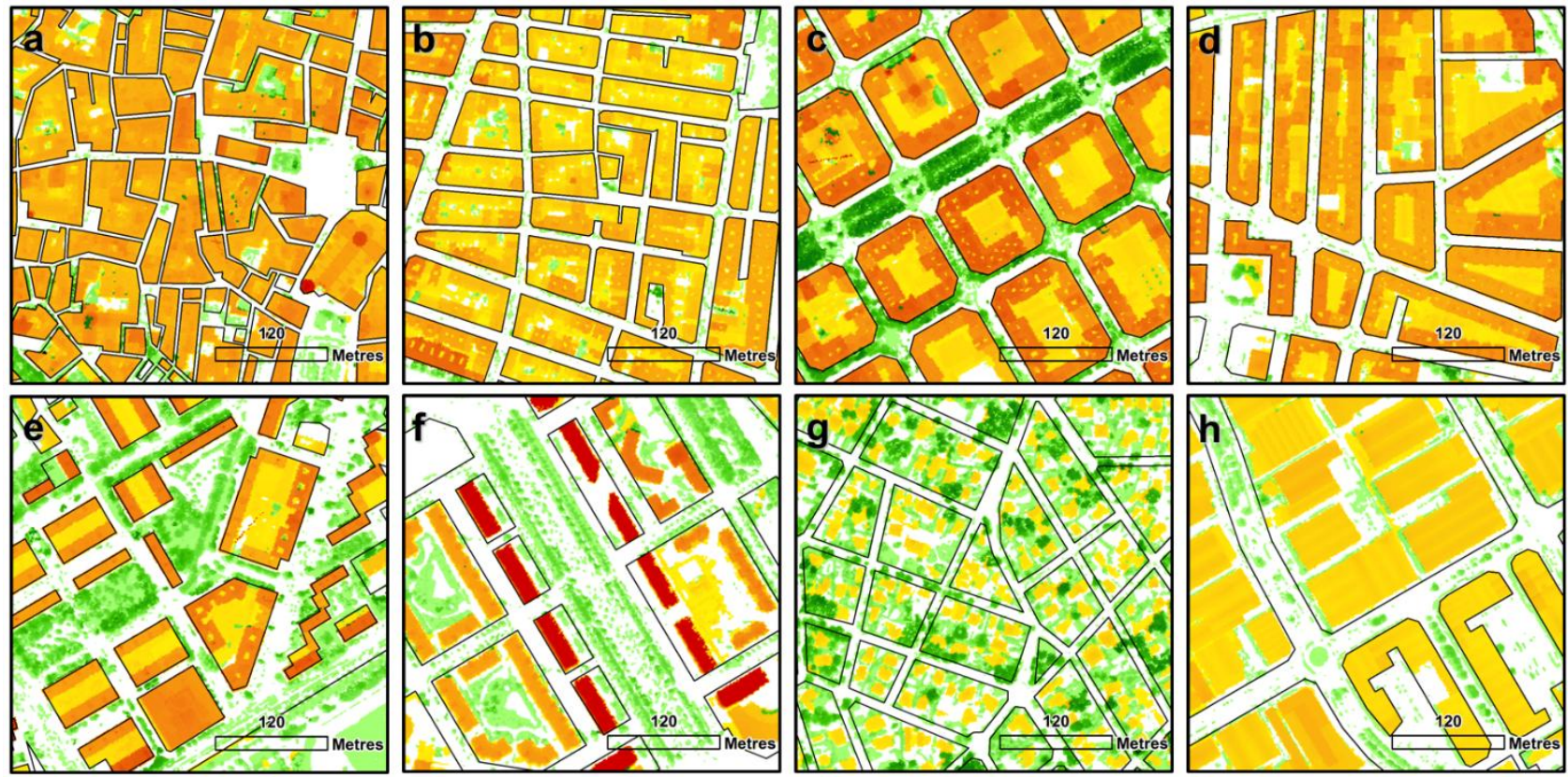

671

Legend: Building height: 0

$50 \mathrm{~m}$

Vegetation height: 0

$20 \mathrm{~m}$

672 Figure 6. Details of buildings and vegetation height distribution for the urban typologies

673 defined: (a) Main historical town (historical1), (b) secondary historical town (historical2), (c)

674 late XIX century expansion $(r X I X)$, (d) 1950-1960s residential areas (r1950-60), (e) 1970-1980s

675 residential areas (r1970-80), (f) 2000s residential areas (r2000), (g) single-family suburban housing areas (suburban), (h) industrial areas (industrial). 
a

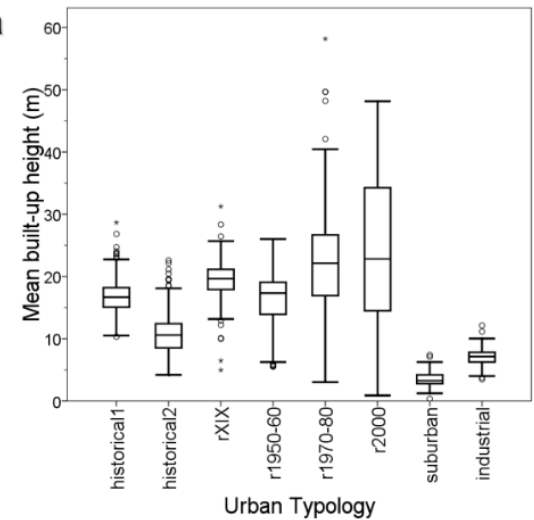

d

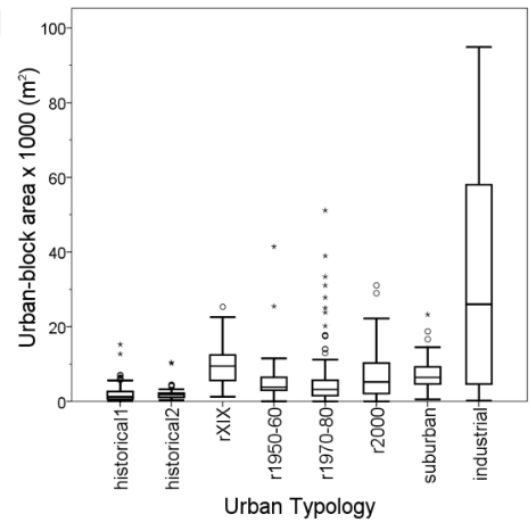

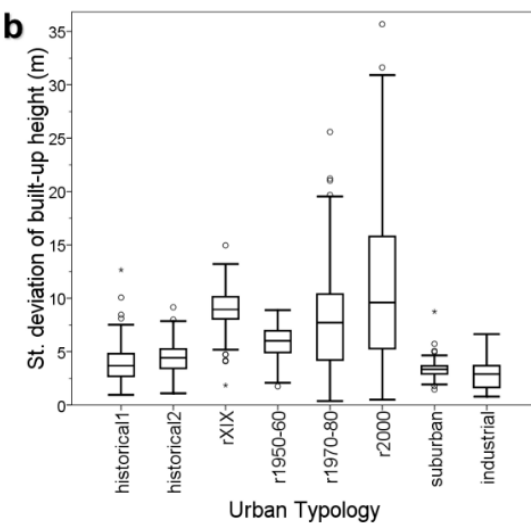

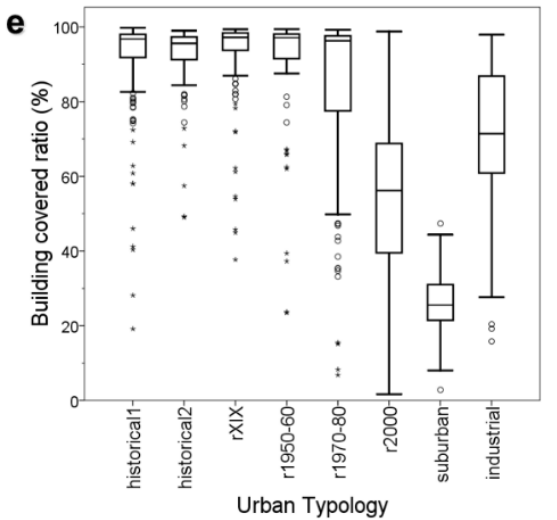

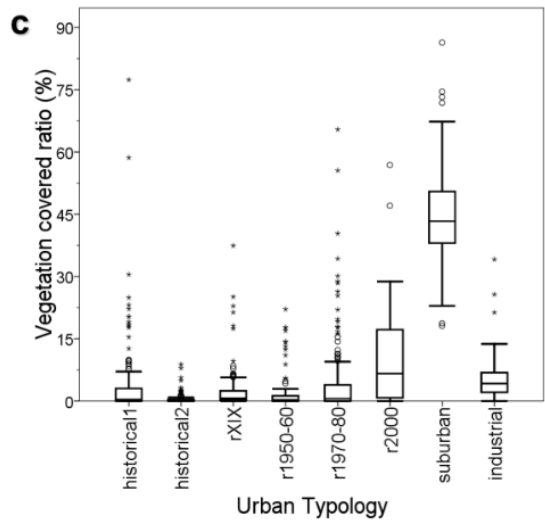

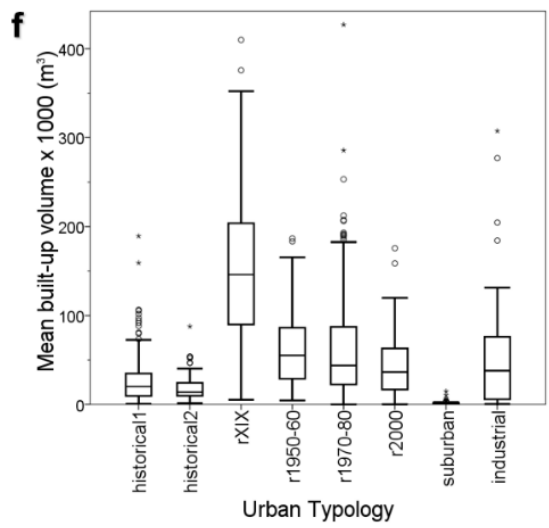

679 Figure 7. Relationship between urban typologies and urban-block metrics: (a) mean built-up 680 height, (b) standard deviation of the built-up heights, (c) vegetation covered ratio, (d) urban681 block area, (e) building covered ratio, and (f) mean built-up volume. 

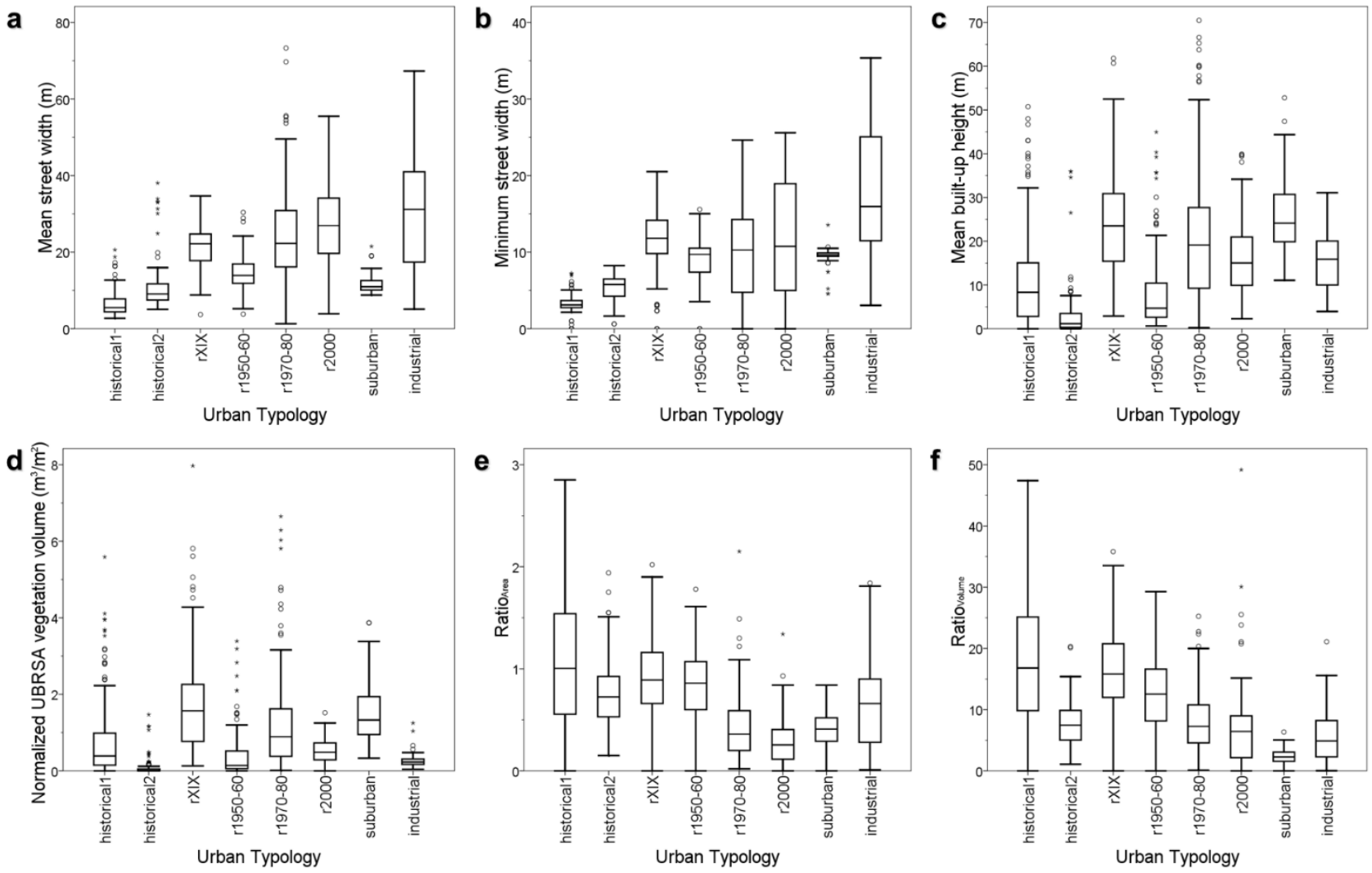

683

Figure 8. Relationship between urban typologies and street metrics: (a) mean street width, (b) 685 minimum street width, (c) UBRSA vegetation covered ratio, (d) normalized UBRSA vegetation 686 covered ratio, (e) ratio between built-up area within an urban block and UBRSA area, and (f) 687 ratio between built-up volume and UBRSA area. 
a

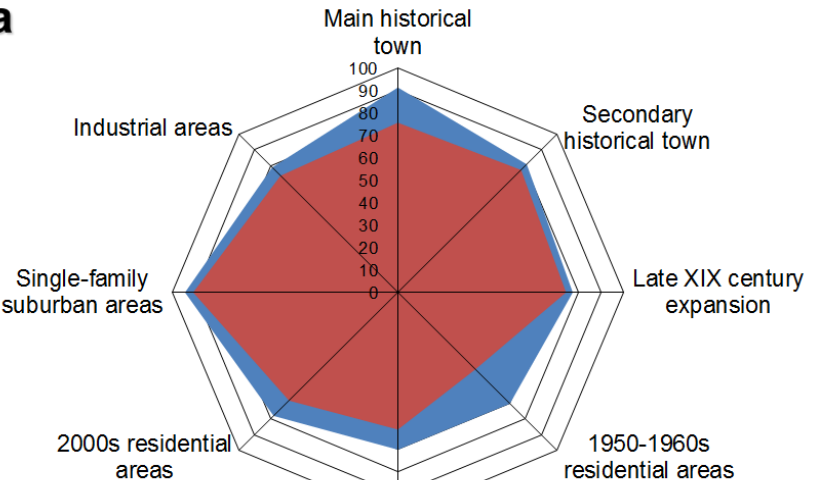
areas residential areas b

Main historical

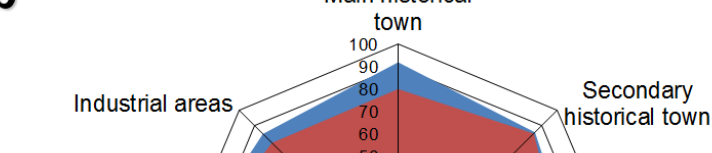
suburban areas

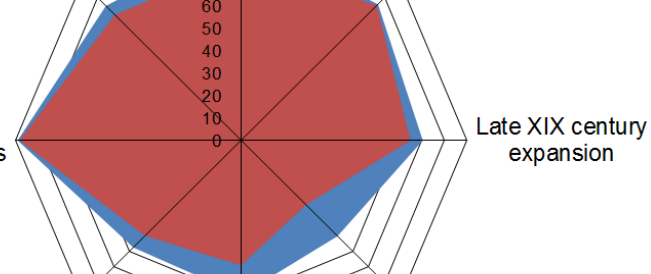

areas 1950-1960s $1970-1980$ s
residential areas

1970-1980s

residential areas

691 Figure 9. (a) User's and (b) producer's accuracies reached for each urban typology when considering only urban-block-based metrics or combining these with street-based metrics. 
Table 1. Metrics and equations extracted from urban blocks.

\begin{tabular}{|c|c|}
\hline Metric (units) & Equation \\
\hline Area $\left(\mathrm{m}^{2}\right)$ & Area $_{U B}$ \\
\hline Perimeter (m) & Perimeter $_{U B}$ \\
\hline Compactness & $C=\frac{4 \cdot \pi \cdot \text { Area }_{U B}}{\text { Perimeter }_{U B}^{2}}$ \\
\hline Shape index & $S I=\frac{\text { Perimeter }_{U B}}{4 \cdot \sqrt{\text { Area }_{U B}}}$ \\
\hline Fractal dimension & $F D=2 \cdot \frac{\log \left(\text { Perimeter }_{U B} / 4\right)}{\log \left(\text { Are }_{U B}\right)}$ \\
\hline Building coverage area $\left(\mathrm{m}^{2}\right)$ & $B C A=\sum^{b} r^{2}$ \\
\hline Building coverage ratio (\%) & $B C R=\frac{B C A}{\text { Area }_{U B}} \cdot 100$ \\
\hline Mean built-up height (m) & $\overline{B H}=\frac{1}{b} \cdot \sum_{i=1}^{b} h_{i}$ \\
\hline Maximum built-up height $(\mathrm{m})$ & $\max B H=\max \left\{h_{i}\right\}$ \\
\hline Standard deviation of building height $(\mathrm{m})$ & $s d B H=\sqrt{\frac{1}{b-1} \cdot \sum_{i=1}^{b}\left(h_{i}-\overline{B H}\right)^{2}}$ \\
\hline Number of buildings & $N_{B}$ \\
\hline Built-up volume $\left(\mathrm{m}^{3}\right)$ & Volume $_{B}=\sum^{b} h_{i} \cdot r^{2}$ \\
\hline Mean built-up volume $\left(\mathrm{m}^{3}\right)$ & $\overline{\text { Volume }}_{B}=\frac{\text { Volume }_{B}}{N_{B}}$ \\
\hline Normalized built-up volume $\left(\mathrm{m}^{3} / \mathrm{m}^{2}\right)$ & nVolume $_{B}=\frac{\text { Volume }_{B}}{\text { Area }_{U B}}$ \\
\hline Vegetation covered area $\left(\mathrm{m}^{2}\right)$ & $V C A=\sum^{v} r^{2}$ \\
\hline Vegetation covered ratio $(\%)$ & $V C R=\frac{V C A}{\text { Area }_{U R}} \cdot 100$ \\
\hline Vegetation volume $\left(\mathrm{m}^{3}\right)$ & Volume $_{V}=\sum^{\mathcal{v}} h_{i} \cdot r^{2}$ \\
\hline Normalized vegetation volume $\left(\mathrm{m}^{3} / \mathrm{m}^{2}\right)$ & nVolume $_{V}=\frac{\text { Volume }_{V}}{\text { Area }_{U B}}$ \\
\hline
\end{tabular}


Table 2. Metrics computed from the UBRSA.

\begin{tabular}{|c|c|}
\hline Metric (units) & Formula \\
\hline UBRSA area $\left(\mathrm{m}^{2}\right)$ & Area $_{U B R S A}$ \\
\hline Mean street width (m) & $\overline{S W}=\frac{1}{n} \cdot \sum_{i=1}^{n} w_{i}$ \\
\hline Standard deviation street width (m) & $s d S W=\sqrt{\frac{1}{n-1} \cdot \sum_{i=1}^{n}\left(w_{i}-\overline{S W}\right)^{2}}$ \\
\hline Maximum street width $(\mathrm{m})$ & $\max S W=\max \left\{w_{i}\right\}$ \\
\hline Minimum street width (m) & $\operatorname{minS} W=\min \left\{w_{i}\right\}$ \\
\hline Number of neighbouring urban blocks & $N N_{U B}$ \\
\hline UBRSA vegetation covered area $\left(\mathrm{m}^{2}\right)$ & $V C A_{U B R S A}=\sum_{i=1}^{v} r^{2}$ \\
\hline UBRSA vegetation covered ratio $\left(\mathrm{m}^{2}\right)$ & $V C R_{U B R S A}=\frac{V C A_{U B R S A}}{\text { Area }_{U B R S A}} \cdot 100$ \\
\hline UBRSA vegetation volume $\left(\mathrm{m}^{3}\right)$ & Volume $_{V U B R S A}=\sum_{i=1}^{v} h_{i} \cdot r^{2}$ \\
\hline Normalized UBRSA vegetation volume $\left(\mathrm{m}^{3} / \mathrm{m}^{2}\right)$ & nVolume $_{\text {VUBRSA }}=\frac{V_{V U B R S A}}{\text { Area }_{U B R S A}}$ \\
\hline $\begin{array}{l}\text { Ratio between the area of the buildings in a urban block } \\
\text { and the area of the UBRSA }\end{array}$ & Ratio $_{\text {Area }}=\frac{B C A}{\text { Area }_{U B R S A}}$ \\
\hline $\begin{array}{l}\text { Ratio between the built-up volume and the area of the } \\
\text { UBRSA }\left(\mathrm{m}^{3} / \mathrm{m}^{2}\right)\end{array}$ & Ratio $_{\text {Volume }}=\frac{\text { Volume }_{B}}{\text { Area }_{U B R S A}}$ \\
\hline
\end{tabular}
$n$ : number of adjacent street segments; $w_{i}$ : street width of adjacent street segment $i ; r$ : spatial resolution; $h_{i}$ : relative height obtained from the nDSM for the pixel $i$; $v$ : number of pixels covered by vegetation within the UBRSA. 
Table 3. Statistically significant different groups determined with Fisher's least significant

704 difference procedure with a 95\% of confidence level. Homogenous groups are identified using

705 the same capital letter and sorted according their magnitude.

\begin{tabular}{|c|c|c|c|c|c|c|c|c|}
\hline Metric & historical1 & historical2 & $r X I X$ & $\begin{array}{l}r 1950 \\
-60 \\
\end{array}$ & $\begin{array}{l}r 1970 \\
-80 \\
\end{array}$ & $r 2000$ & suburban & industrial \\
\hline Area $_{U B}$ & A & A & $\mathrm{C}$ & $\mathrm{B}$ & $\mathrm{B}$ & $\mathrm{BC}$ & $\mathrm{B}$ & $\mathrm{D}$ \\
\hline Perimeter $_{U B}$ & A & A & $\mathrm{C}$ & B & B & B & B & $\mathrm{D}$ \\
\hline Compactness & B & B & $\mathrm{D}$ & B & $\mathrm{A}$ & B & $\mathrm{C}$ & B \\
\hline Shape index & B & B & A & B & $\mathrm{C}$ & $\mathrm{C}$ & A & B \\
\hline Fractal Dim. & $\mathrm{C}$ & $\mathrm{C}$ & A & $\mathrm{C}$ & $\mathrm{D}$ & $\mathrm{E}$ & $\mathrm{AB}$ & $\mathrm{BC}$ \\
\hline$B C A$ & A & A & $\mathrm{D}$ & $\mathrm{C}$ & $\mathrm{C}$ & $\mathrm{BC}$ & $\mathrm{AB}$ & $\mathrm{E}$ \\
\hline$B C R$ & E & $\mathrm{E}$ & $\mathrm{E}$ & $\mathrm{DE}$ & $\mathrm{D}$ & $\mathrm{B}$ & A & $\mathrm{C}$ \\
\hline$\overline{B H}$ & $\mathrm{D}$ & $\mathrm{C}$ & $\mathrm{E}$ & $\mathrm{D}$ & $\mathrm{F}$ & $\mathrm{G}$ & A & B \\
\hline $\max B H$ & $\mathrm{C}$ & B & $\mathrm{D}$ & $\mathrm{C}$ & $\mathrm{D}$ & $\mathrm{E}$ & A & B \\
\hline$s d B H$ & $\mathrm{AB}$ & $\mathrm{B}$ & $\mathrm{D}$ & $\mathrm{C}$ & $\mathrm{D}$ & E & A & A \\
\hline$N_{B}$ & $\mathrm{~A}$ & $\mathrm{AB}$ & $\mathrm{AB}$ & $\mathrm{AB}$ & $\mathrm{BC}$ & $\mathrm{C}$ & $\mathrm{E}$ & $\mathrm{D}$ \\
\hline Volume $_{B}$ & B & $\mathrm{AB}$ & $\mathrm{D}$ & $\mathrm{C}$ & $\mathrm{C}$ & $\mathrm{C}$ & A & $\mathrm{E}$ \\
\hline$\overline{\text { Volume }}_{B}$ & B & B & $\mathrm{E}$ & $\mathrm{D}$ & $\mathrm{D}$ & $\mathrm{C}$ & A & $\mathrm{CD}$ \\
\hline nVolume $_{B}$ & $\mathrm{CD}$ & $\mathrm{BC}$ & $\mathrm{CD}$ & $\mathrm{BCD}$ & $\mathrm{D}$ & $\mathrm{E}$ & A & $\mathrm{AB}$ \\
\hline$V C A$ & A & A & $\mathrm{AB}$ & $\mathrm{AB}$ & B & $\mathrm{C}$ & $\mathrm{E}$ & $\mathrm{D}$ \\
\hline$V C R$ & $\mathrm{BC}$ & A & B & $\mathrm{AB}$ & $\mathrm{BC}$ & $\mathrm{D}$ & E & $\mathrm{C}$ \\
\hline Volume $_{V}$ & $\mathrm{AB}$ & A & $\mathrm{C}$ & $\mathrm{ABC}$ & $\mathrm{C}$ & $\mathrm{BC}$ & $\mathrm{D}$ & $\mathrm{C}$ \\
\hline nVolume $_{V}$ & $\mathrm{BCD}$ & $\mathrm{A}$ & $\mathrm{BCD}$ & $\mathrm{AB}$ & $\mathrm{D}$ & $\mathrm{CD}$ & $\mathrm{E}$ & $\mathrm{ABC}$ \\
\hline Area $_{U B R S A}$ & A & $\mathrm{A}$ & $\mathrm{C}$ & $\mathrm{B}$ & $\mathrm{C}$ & $\mathrm{D}$ & B & $\mathrm{E}$ \\
\hline$\overline{S W}$ & A & B & $\mathrm{D}$ & $\mathrm{C}$ & $\mathrm{E}$ & $\mathrm{E}$ & $\mathrm{B}$ & $\mathrm{F}$ \\
\hline$s d S W$ & $\mathrm{AB}$ & $\mathrm{BC}$ & $\mathrm{D}$ & $\mathrm{C}$ & $\mathrm{E}$ & $\mathrm{E}$ & $\mathrm{A}$ & $\mathrm{E}$ \\
\hline $\max S W$ & $\mathrm{~A}$ & $\mathrm{BC}$ & $\mathrm{D}$ & $\mathrm{C}$ & $\mathrm{E}$ & $\mathrm{E}$ & $\mathrm{AB}$ & $\mathrm{E}$ \\
\hline $\min S W$ & A & B & $\mathrm{F}$ & $\mathrm{C}$ & $\mathrm{DE}$ & $\mathrm{EF}$ & $\mathrm{CD}$ & $\mathrm{G}$ \\
\hline$N N_{U B}$ & $\mathrm{E}$ & A & $\mathrm{DE}$ & $\mathrm{CDE}$ & $\mathrm{BCD}$ & $\mathrm{BC}$ & B & $\mathrm{BCDE}$ \\
\hline$V C A_{U B R S A}$ & A & A & $\mathrm{C}$ & $\mathrm{AB}$ & $\mathrm{C}$ & $\mathrm{C}$ & B & $\mathrm{D}$ \\
\hline$V C R_{U B R S A}$ & B & $\mathrm{A}$ & $\mathrm{E}$ & B & $\mathrm{D}$ & $\mathrm{C}$ & $\mathrm{E}$ & $\mathrm{C}$ \\
\hline Volume $_{V U B R S A}$ & A & A & $\mathrm{C}$ & $\mathrm{AB}$ & $\mathrm{C}$ & B & B & B \\
\hline nVolume $_{V U B R S A}$ & $\mathrm{C}$ & A & $\mathrm{F}$ & B & $\mathrm{D}$ & $\mathrm{BC}$ & $\mathrm{E}$ & $\mathrm{AB}$ \\
\hline Ratio $_{\text {Area }}$ & $\mathrm{F}$ & $\mathrm{D}$ & $\mathrm{E}$ & $\mathrm{DE}$ & B & A & $\mathrm{AB}$ & $\mathrm{D}$ \\
\hline Ratio $_{\text {Volume }}$ & $\mathrm{F}$ & $\mathrm{C}$ & E & $\mathrm{D}$ & $\mathrm{C}$ & $\mathrm{BC}$ & $\mathrm{A}$ & $\mathrm{B}$ \\
\hline
\end{tabular}


Table 4. Attributes selected by the winnow algorithm ranked by their classification significance

709 considering only urban block metrics, or combining these with street metrics (identified with *)

\begin{tabular}{|c|c|c|c|}
\hline \multicolumn{2}{|c|}{ Urban block metrics } & \multicolumn{2}{|c|}{ Urban block \& Street metrics } \\
\hline Metric & Significance & Metric & Significance \\
\hline VCR & $33 \%$ & $* \overline{\mathrm{SW}}$ & $44 \%$ \\
\hline$\overline{\mathrm{BH}}$ & $24 \%$ & VCR & $42 \%$ \\
\hline Compactness & $10 \%$ & $\overline{\mathrm{BH}}$ & $40 \%$ \\
\hline sdBH & $10 \%$ & $\mathrm{BCR}$ & $9 \%$ \\
\hline Perimeter $_{\mathrm{UB}}$ & $8 \%$ & $*$ Ratio $_{\text {Area }}$ & $5 \%$ \\
\hline BCR & $8 \%$ & $* \mathrm{VCR}_{\mathrm{UBRSA}}$ & $3 \%$ \\
\hline Area $_{U B}$ & $4 \%$ & Perimeter $_{\mathrm{UB}}$ & $1 \%$ \\
\hline Volume $_{\mathrm{V}}$ & $3 \%$ & nVolume $_{\mathrm{V}}$ & $1 \%$ \\
\hline Fractal dimension & $2 \%$ & $*_{\max } \mathrm{WW}$ & $1 \%$ \\
\hline $\operatorname{maxBH}$ & $2 \%$ & $*_{\text {nVolume }}$ VUBRSA & $1 \%$ \\
\hline $\mathrm{BCA}$ & $1 \%$ & Fractal dimension & $<1 \%$ \\
\hline Volume $_{\mathrm{B}}$ & $1 \%$ & Volume $_{\mathrm{B}}$ & $<1 \%$ \\
\hline $\mathrm{N}_{\mathrm{B}}$ & $1 \%$ & $* \mathrm{NN}_{\mathrm{UB}}$ & $<1 \%$ \\
\hline nVolume $_{\mathrm{B}}$ & $1 \%$ & *Area ${ }_{\text {UBRSA }}$ & $<1 \%$ \\
\hline Shape Index & $<1 \%$ & $*$ Ratio ${ }_{\text {Volume }}$ & $<1 \%$ \\
\hline VCA & $<1 \%$ & & \\
\hline nVolume $_{\mathrm{V}}$ & $<1 \%$ & & \\
\hline
\end{tabular}


712 Table 5. Overall classification accuracy reached considering only urban block metrics or 713 combining these with street metrics.

\begin{tabular}{|ll|}
\hline Urban metrics & Overall accuracy \\
\hline Urban bock & $72.7 \%$ \\
Urban block \& Street & $81.1 \%$ \\
\hline
\end{tabular}

714 